\title{
The analysis of flow behavior of Ti-6Al-2Sn-4Zr-6Mo alloy based on the processing maps
}

\author{
Oleksandr Lypchanskyi ${ }^{1}$ (I) Tomasz Śleboda $^{1}$ (D) - Marek Wojtaszek ${ }^{1}$ (I) $\cdot$ \\ Krzysztof Muszka $^{1}$ (1) $\cdot$ Aneta Łukaszek-Sołek $^{1}$ (D) $\cdot$ Rafał Stanik $^{2}$ (D) $\cdot$ Maik Gude $^{2}$ (D)
}

Received: 4 March 2019 / Accepted: 18 December 2019 / Published online: 14 January 2020

(C) The Author(s) 2020

\begin{abstract}
The paper presents the analysis of hot deformation behavior of Ti-6Al-2Sn-4Zr-6Mo (Ti-6246) alloy using the theory of dynamic material modeling (DMM) based on hot compression tests performed to a total true strain of 1 at the strain rates from 0.01 to $100 \mathrm{~s}^{-1}$ and at the temperatures within the range between 800 and $1100{ }^{\circ} \mathrm{C}$. The processing maps according to the Prasad's criterion were developed. The analysis of the processing maps allowed for the placement of domains describing the areas of potentially favorable combinations of hot deformation parameters. The microstructure observations of the investigated alloy specimens after hot deformation in stability and instability areas were conducted. The optimal processing parameters for numerical modeling of Ti-6246 alloy forging were selected based on processing maps. After complex analysis of the obtained results, microstructural observations and numerical modeling of forging of selected part, the forging tests of Ti-6246 alloy were realized. The obtained product quality assessment was carried out by computed tomography non-destructive testing.
\end{abstract}

Keywords Ti-6246 alloy $\cdot$ Processing maps $\cdot$ Microstructure $\cdot$ Forging $\cdot$ Computed tomography

\section{Introduction}

The Ti-6Al-2Sn-4Zr-6Mo (Ti-6246) alloy belongs to the group of $\alpha+\beta$ alloys characterized by long-term high strength properties at elevated temperatures and susceptibility to heat treatment such as aging and solution treatment. It is used for the production of the gas turbine parts working at intermediate temperature such as compressor disks and blades [1-3].

Hot die forging is commonly used for producing good quality Ti-6246 components having good mechanical properties and therefore appropriate for many applications. The microstructure of Ti-6246 alloy includes primary $\alpha_{p}$ and secondary $\alpha_{s}$ phase with $\beta$ phase matrix $[4,5]$. The temperature of $\beta$ transus is about $950{ }^{\circ} \mathrm{C}[6,7]$. For controlling the microstructure and final

Oleksandr Lypchanskyi

lypchans@agh.edu.pl

1 AGH University of Science and Technology, Faculty of Metals Engineering and Industrial Computer Science, Av. Mickiewicza 30, 30-059 Krakow, Poland

2 Institute of Lightweight Engineering and Polymer Technology (ILK), Technische Universität Dresden, Dresden, Germany properties of Ti-6246 alloy, it is very important to determine the precise deformation conditions. The occurrence of the $\alpha$ phase in the microstructure reduces the growth of $\beta$ phase grains during plastic deformation, and increasing deformation temperature increases an advancement of the recrystallization proces of $\beta$ phase [5]. The authors of work [6] noted the effect of breaking up and partially dissolving primary $\alpha$-lamellae and $\alpha$ precipitations within $\beta$ matrix as a result of heating up to high temperature ranges in $\alpha+\beta$ region. It was also noticed, that lower strain rates lead to almost complete dissolution of $\alpha$ plates in $\beta$ matrix. Moreover, the amount and distribution of untransformed $\alpha$ phase and $\beta$ phase result from thermal treatments like solution treatment and aging [7]. The study of evolution of the microstructure and subsequent phase transformations at hot deformation temperatures below $\beta$ transus [8] showed the influence of this temperature on the morphology of the resulting phases and $\beta$ to $\alpha$ phase transformation kinetics. It was also noticed, that during slow cooling, the transformation kinetics of deformed material was accelerated as compared with the transformation kinetics of undeformed structure. As mentioned in [9], a constant load practically has no influence on fatigue life of Ti-6246 alloy.

As the literature review shows the understanding of hot deformation mechanism of the titanium alloys is integral part to optimize their chemistry and processing parameters 
[10]. To solve this problem, the processing maps developed on the basis of the theory of dynamic material modeling (DMM) in conjunction with various criteria are often used [11-16]. The results of the comparative analysis of various instability criteria for Ti-22Al- $25 \mathrm{Nb}$ alloy were presented by Ma et al. [17]. The authors claimed that the Murty's and Prasad's criterions are more effective for predicting the instability of plastic flow. The similar conclusions were made for superalloy GH79 by Zhou [18]. Moreover, the authors also emphasize a need for further experimental research for validation of their conclusions. Wu et al. as well as Yang et al. [19, 20] indicated similar results in predicting the hot workability of Ti-55 high-temperature titanium alloy and for high strength automobile steel Docol 1500 Bor using an approach proposed by Prasad and Murty. Lypchanskyi et al. [21] investigated the hot deformation behavior of Ti-6Al-2Sn4Zr-6Mo alloy using processing maps based on the Malas's criterion. However, Li et al. [16] showed the superiority of prediction accuracy of the Murty and the Prasad criteria over the Malas criterion. Ma et al. [22] also noted higher reliability in identifying unstable areas according to the criteria of Prasad and Murthy for Ti-17 alloy. The processing maps are obtained by superimposing the combination of a power dissipation efficiency map $(\eta)$ on the parameter of flow instability $(\xi)$. According to DMM theory the hot deformation is a result of power dissipation. The largest part of the total power $P$ is dissipated as temperature increase during hot deformation $(G)$ and the rest $(J)$ is attributed to the microstructure transition, such as phase transformations, dynamic recrystallization (DRX) and dynamic recovery (DRV) [11, 12, 23, 24]. The total power $P$ can be described as [11]:

$P=\sigma \cdot \dot{\varepsilon}=G+J=\int_{0}^{\varepsilon} \sigma d \dot{\varepsilon}+\int_{0}^{\sigma} \dot{\varepsilon} d \sigma$

where $\sigma$ is the flow stress (MPa), and $\varepsilon$ is the strain rate $\left(\mathrm{s}^{-1}\right)$. The strain rate sensitivity parameter $(m)$ is a binding parameter for determining the relative partitioning of power between microstructural changes and heat generation [24, 25].

$m=(\partial J / \partial G)_{T, \varepsilon}=\frac{\sigma d \dot{\varepsilon}}{\dot{\varepsilon} d \sigma}=\left(\frac{\partial \ln \sigma}{\partial \ln \dot{\varepsilon}}\right)_{T, \varepsilon}$

where: $T$ is temperature $\left({ }^{\circ} \mathrm{C}\right)$, and $\varepsilon$ is constant true strain value.

The power dissipation resulting from the microstructure transition $J$ can be described as $[25,26]$ :

$J=\int_{0}^{\sigma} \dot{\varepsilon} d \sigma=\frac{\sigma \cdot \dot{\varepsilon} \cdot m}{m+1}$

Under ideal conditions of plastic flow, when $m=1$ and $J=$ $J_{\max }=P / 2$, the efficiency of power dissipation $\eta$ can be evaluated by $[11,12,25,26]$ :
$\eta=J / J_{\max }=2 m /(m+1)$

The variation of the efficiency of power dissipation $\eta$ is represented in the form of power dissipation map and depends on the change of strain rate, deformation temperature and strain rate sensitivity. This map displays the characteristics of power dissipation resulting from the microstructure evolution. The higher value of $\eta$ corresponds to the desired domains for hot working, because it reflects the large power dissipated due to microstructure evolution. However, the criterion for the occurrence of flow instabilities $\xi$ during hot working should also be taken into account [22].

$\xi(\dot{\varepsilon})=\frac{\partial \ln \left(\frac{m}{m+1}\right)}{\partial \ln \dot{\varepsilon}}+m \leq 0$

The instability maps are the variations of $\xi$ with the temperature and strain rate. They are indicative of the flow instability in deformation at different conditions and can be used to optimize the process parameters during thermomechanical processing of metallic materials.

\section{Experimental procedures}

The chemical composition of the investigated Ti-6246 alloy is given in Table 1. Compressive specimens had the shape of a cylinder with $10 \mathrm{~mm}$ in diameter and $12 \mathrm{~mm}$ in height. They were cut out from a $50 \mathrm{~mm}$ diameter rod parallel to the rod axis. The hot compression tests were conducted under vacuum atmosphere on Gleeble 3800 thermomechanical simulator at the temperatures of $800,900,950,1000$ and $1100{ }^{\circ} \mathrm{C}$, and under the strain rates of $0.01,0.1,1,10$ and $100 \mathrm{~s}^{-1}$. During compression a reduction of the instantaneous sample height was taken into account. Typically, the compression test can be conducted without barreling to $\sim 50 \%$ height reduction (true strain 0.69) or more. In the performed tests the samples were deformed in compression to a total true strain of 1 and some barreling at the final stage of deformation occurred. Barreling of the test specimens during compression cannot be entirely eliminated because there is always friction between the specimen and the tooling. In order to minimize the friction effects during deformation, the graphite foil was used for the hot compression tests. The specimens were heated up at the heating rate of $2.5^{\circ} \mathrm{C} / \mathrm{s}$, up to deformation temperature, then held at this temperature. Then, the compressed samples were quenched at the cooling rate of $10{ }^{\circ} \mathrm{C} / \mathrm{s}$ in compressed air. In

Table 1 Chemical composition of the investigated Ti-6246 alloy

\begin{tabular}{lllllllll}
\hline Composition & $\mathrm{C}$ & $\mathrm{Si}$ & $\mathrm{Mo}$ & $\mathrm{Al}$ & $\mathrm{Fe}$ & $\mathrm{Sn}$ & $\mathrm{Zr}$ & $\mathrm{Ti}$ \\
\hline Content (at \%) & 0.01 & 0.09 & 6.18 & 6.13 & 0.09 & 1.8 & 3.8 & Bal. \\
\hline
\end{tabular}


order to correct the flow curve and to determine the percentage error in flow stress, finite element (FE) analysis was used.

The initial microstructure of the investigated Ti-6246 alloy (Fig. 1(a-b)) was observed using electron backscatter diffraction method (EBSD). The microstructure is characterized by a high uniformity and constituted of spheroidal and dispersive primary $\alpha_{p}$ phase with the volume fraction of $40-45 \%$ in $\beta$ matrix containing small needles of secondary $\alpha_{\mathrm{s}}$ phase. The average diameter of $\alpha_{p}$ phase grains was of about $5 \mu \mathrm{m}$.

Based on the results from experimental part of the work, numerical simulation of forging of component made of studied alloy was performed. QForm 2D/3D commercial software was used in this study for the numerical analysis of forging of selected Ti-6246 alloy part. The flow stress curves obtained from isothermal hot compression tests were used for the description of the material behavior during FE simulations. Load-displacement data recorded during Gleeble compression tests were an input for the inverse analysis. After correction performed using custom FE code the stress-strain data were entered into the program. Specific heat and thermal conductivity curves for Ti-6246 alloy were obtained experimentally in Differential Scanning Calorimetry (DCS) and Laser Flash Apparatus (LFA) tests. The friction coefficient was determined in ring compression tests. Calculation of friction in QForm program is based on Levanov's first friction law with combination of Tresca's and Columb's laws. The boundary conditions assumed the use of two forging stages performed on $25 \mathrm{~kJ}$ hammer and glass lubricant with friction coefficient $\mu$ of 0.06 . The selection of the optimal deformation temperature was made according to the processing maps obtained on the basis of the flow stress curves. These flow stress curves were also used for the description of the material behavior during numerical modeling. The assumed temperature of tools used in the forging process modeling was $250{ }^{\circ} \mathrm{C} .71 \mathrm{~mm}$ in height and $50 \mathrm{~mm}$ in diameter billet was used as initial material for processing. The time of billet transportation and cooling in a die was also taken into account and was $2 \mathrm{~s}$ and $1 \mathrm{~s}$ respectively. Verification of the obtained results was carried out on the basis of the forging tests of Ti-6246 alloy realized at ATI ZKM Forging Company, Stalowa Wola, Poland. For the analysis of the quality of the obtained part the computed tomography (CT), as one of the nondestructive testing methods, was used. CT testing was performed at the Institute of Lightweight Engineering and Polymer Technology (ILK) of Technische Universität Dresden. The high resolution CT-system V|tome|x-L 450 (GE Phoenix X-ray) was used for non-destructive testing. The maximal resolution of the CT-system is $1 \mu \mathrm{m}$. The resolution applied in performed CT testing of forged part was $50 \mu \mathrm{m}$.

\section{Results and discussion}

\section{Flow behavior}

Figure 2 shows the stress-strain curves obtained for Ti-6246 alloy in compression tests under each testing condition. As it can be seen from the flow curves, with the increase of deformation temperature and decrease of strain rate, the flow stress decreases. The flow curves obtained from compression tests are characterized by a rapid increase of the flow stress at the beginning of plastic deformation till a peak stress is reached, and the subsequent decrease to a stable state (Fig. 2(a-c)). In this case the material exhibits softening behavior and this may be due to the occurrence of DRX. After the peak stress is reached, the level of stress remains almost unchanged with increasing strain and increasing deformation temperature (Fig. 2(d-e)).

\section{Processing maps}

According to the Eq. (3) the variations of the instantaneous power dissipated $J$ co-content (Fig. 3) at different temperatures and strain rates at constant strain value was obtained. Prasad et al. [11] showed that processes such as dynamic recrystallization or dynamic recovery influence the changes in the dissipated power co-content $J$. Each visible change in
Fig. 1 EBSD map of the microstructure of Ti-6246 alloy used in the investigations observed in longitudinal crosssection: (a) primary $\alpha_{p}$ phase and secondary $\alpha_{\mathrm{s}}$ phase (bright areas) and the $\beta$ phase (dark areas), (b) $\beta$ phase (light green areas) and the primary $\alpha_{\mathrm{p}}$ phase, and secondary $\alpha_{\mathrm{s}}$ phase (red regions)
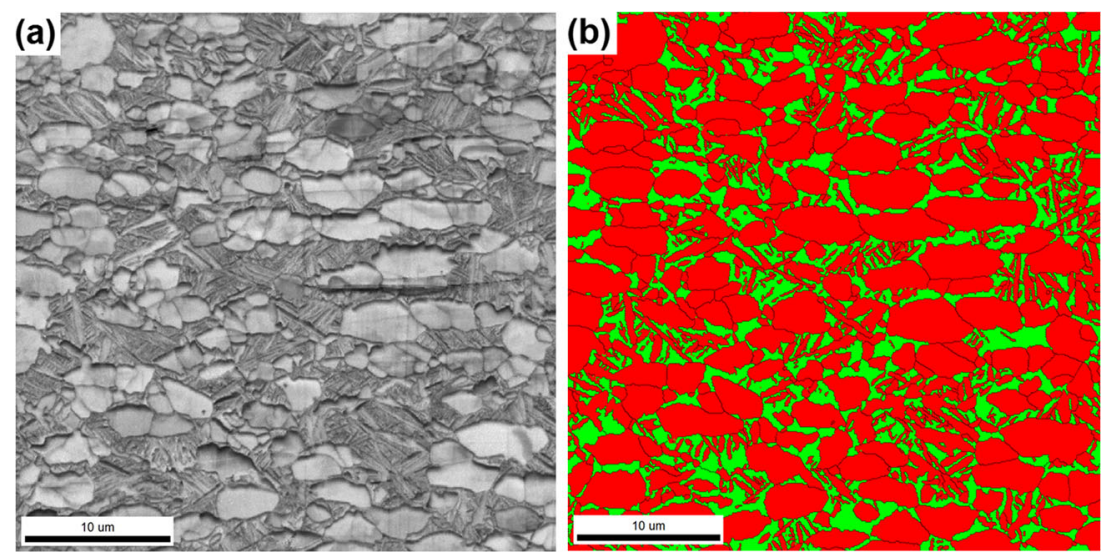

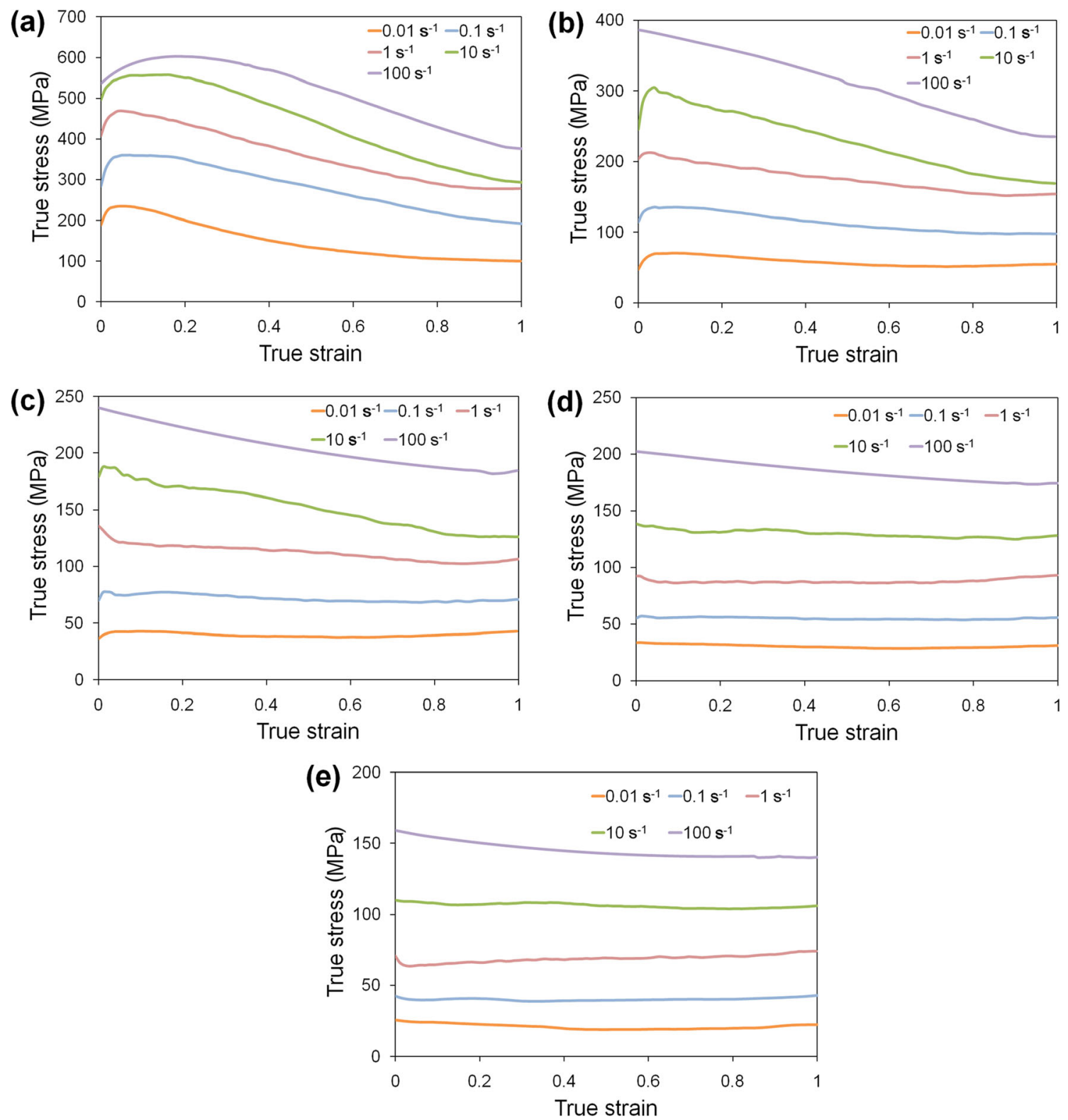

Fig. 2 The flow stress curves for Ti-6246 alloy obtained from compression tests performed to a total true strain of 1 at different temperatures: (a) 800 , (b) 900, (c) 950, (d) 1000 , (e) $1100{ }^{\circ} \mathrm{C}$

the slope of the line representing the component of $J$ cocontent may signify the disturbance in alloy flow during plastic forming.

The processing maps for Ti-6246 alloy, obtained on the basis of the flow stress curves presented in Fig. 2, are shown in Fig. 4. They were elaborated in accordance with the Prasad criteria for a true strain of $0.2,0.4,0.6,0.8$ and 1 . These maps represent the values of the efficiency of power dissipation $\eta \%$ shown as numbers on isoclines (black lines). Dark domains reflect the plastic flow instability region where $\xi \leq 0$. The slight change in instability domains indicates the steady state of strain and these regions should be avoided considering processing parameters. The analysis of the distribution of isoclines shows, that the decrease of strain rate increases the values of the efficiency of power dissipation, what corresponds to the results shown in other works [11, 27-29]. It should be noted, that the stability domains are observed at low strain rates with high $\eta$ values, and these conditions can be considered as optimal. The maximum values of the efficiency of power dissipation $\eta$ is concentrated in domains with the lowest strain rate and temperature of $900{ }^{\circ} \mathrm{C}$ (Fig. 4(a)), and of $800{ }^{\circ} \mathrm{C}$ (Fig. 4(b-e)). Therefore, the workability of Ti-6246 alloy in these domains should be improved due to the higher value of $\eta$, reflecting the large power dissipated by the microstructure. It should also be noted, that almost all processing maps have characteristic change in a curvature of power dissipation efficiency contour lines 


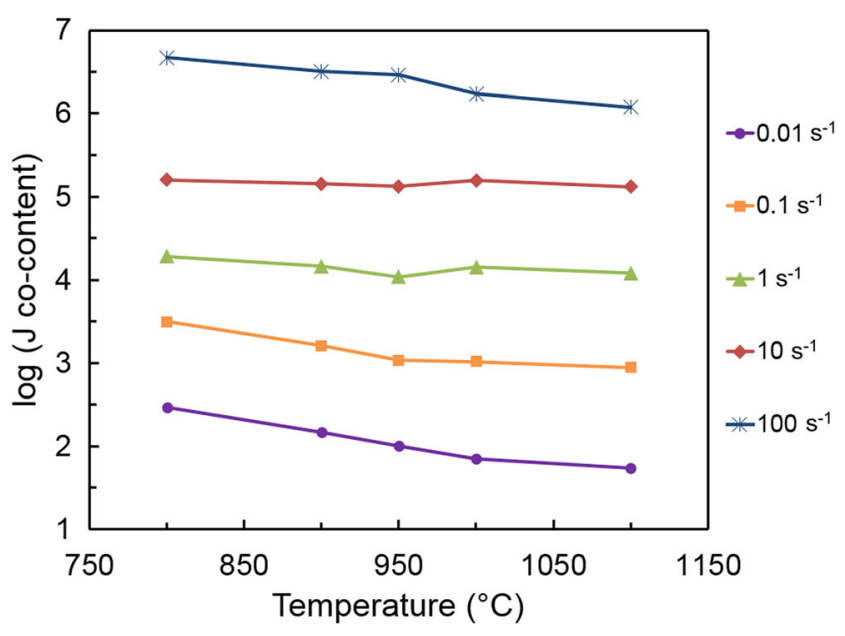

Fig. 3 The distribution of $J$ co-content as a function of temperature at different strain rates for the true strain of 1.0

around the temperature of $950{ }^{\circ} \mathrm{C}$, what is most likely connected with the temperature of $\beta-\alpha$ transition also noted by Jackson et al. [6] and Tarín et al. [7].

Besides, the high peak of power dissipation efficiency is often considered as evidence of safe deformation behavior such as DRX, DRV and superplasticity [12, 27-29]. The DRX can be attributed to processes that increase the hot workability of alloy. The value of power dissipation efficiency for occurrence of DRX is considered to be within 30-50\% range, while the values over $60 \%$ are often associated with superplasticity. The smaller values of $\eta(20-30 \%)$ are often associated with DRV [26].

Figure 4 shows the domain with the maximum efficiency of power dissipation of $50 \%$ at the temperature of $900{ }^{\circ} \mathrm{C}$ and strain rate of $0.01 \mathrm{~s}^{-1}$, what is typical for DRX process. With the increasing true strain another domain is formed, having a higher value of power dissipation efficiency and covering a wider range of temperatures and strain rates. Figure 4(b-e) shows the domains with the same location of the temperature range $\left(1075^{\circ} \mathrm{C}-1100{ }^{\circ} \mathrm{C}\right)$ and strain rates $\left(0.01 \mathrm{~s}^{-1}-0.02 \mathrm{~s}^{-1}\right)$ with a peak of power dissipation efficiency in the range of 48 $52 \%$. These domains are interpreted as representing DRX of $\beta$ phase. It should be noted, that in the case of these domains, the phase transformation may affect the visibility of the DRX process in the microstructure. The values of power dissipation efficiency $\eta$ within a range of $20-30 \%$ is typical for domains corresponding to the temperatures of $900{ }^{\circ} \mathrm{C}$ and $950{ }^{\circ} \mathrm{C}$, and strain rate of $100 \mathrm{~s}^{-1}$. This can be observed in almost all processing maps shown in Fig. 4. This deformation behavior of the material can be associated with DRV.

The authors of work [30] noted, that the superplasticity of Ti-6246 alloy can be observed at the temperature of $750{ }^{\circ} \mathrm{C}$ and at the strain rate of $0.01 \mathrm{~s}^{-1}$. The maps shown in Fig. 4(be) have similar stability domains at the strain rates ranging from 0.01 to $0.03 \mathrm{~s}^{-1}$ and at the temperature range of $800-$ $950{ }^{\circ} \mathrm{C}$, with the maximum value of $\eta$ higher than $54 \%$.
Moreover, in the case of maps shown in Fig. 4(c) and Fig. 4(d) this value is greater than $60 \%$. Taking into account the distribution of isoclines in these domains, a possible occurrence of superplasticity can be indicated in this region, what corresponds to the previously discussed results.

The complex processing map for Ti-6246 alloy (Fig. 5) represents the distribution of the plastic flow instability $\xi$ in the form of dashed red isoclines with dark domains (instability domains $\mathrm{A}$ and $\mathrm{B}$ ), and a black isoclines showing values of power efficiency $\eta$ at the true strain of 1 . The analysis of the processing maps (Fig. 4) allows for the placement of domains (processing windows I-III) describing the areas of potentially favorable combinations of hot deformation parameters. The first domain (processing window I), situated within strain rate range of 32-100 s$~^{-1}$ and at the temperature range of 860 $975^{\circ} \mathrm{C}$, has the values of $\eta$ within the range of $22-30 \%$ and $\xi$ within the range of $0.25-0.65$. This area, connected with DRV, is the most optimal for hot deformation of the investigated Ti-6246 alloy at the strain rates $\geq 10 \mathrm{~s}^{-1}$. The next domain (processing window II) is characterized by low strain rates $\left(0.01-0.04 \mathrm{~s}^{-1}\right)$ and a range of processing temperatures of $800-900^{\circ} \mathrm{C}$. In this case, the dense distribution of isoclines of power dissipation efficiency and the highest values (42$56 \%$ ) of this parameter are the desired domains for hot working. Besides the presence of DRX and superplasticity in these areas, the parameters shown in this processing window give the possibility of obtaining a fine-grained structure in the investigated alloy. The smallest, third domain (processing window III) determined by temperature limits $1075-1100^{\circ} \mathrm{C}$ and strain rate in a range of $0.01-0.02 \mathrm{~s}^{-1}$, with the optimal peak value of $\eta$ equal to about $48 \%$, reflects the large power dissipated due to the microstructure evolution.

\section{Microstructural analysis}

The microstructure of Ti-6246 alloy specimens after hot deformation performed according to the parameters corresponding to the instability domains for the temperature of $800{ }^{\circ} \mathrm{C}$, strain rate of $1 \mathrm{~s}^{-1}$, as well as for the temperatures of $1100{ }^{\circ} \mathrm{C}$, and strain rate of $100 \mathrm{~s}^{-1}$ are shown in Fig. 6(a-b), respectively. It is considered, that deformation conducted at flow instability conditions usually results in cracking or flow localization. In this case, the Fig. 6(a) demonstrates the flow localization bands in the area of plastic flow instability (domain A, Fig. 5), what corresponds to one of the stages of adiabatic shear banding described by Prasad and Seshacharyulu [12]. Due to further deformation, the presence of this localization can lead to shear cracks. Quite often, the flow instability is observed at a high strain rates, what is clearly visible in Fig. 6(b) and Fig. 5 (domain B). As can be seen from these figures, $\alpha$ phase grains are concentrated to a greater extent in the region of the most intense flow of the 

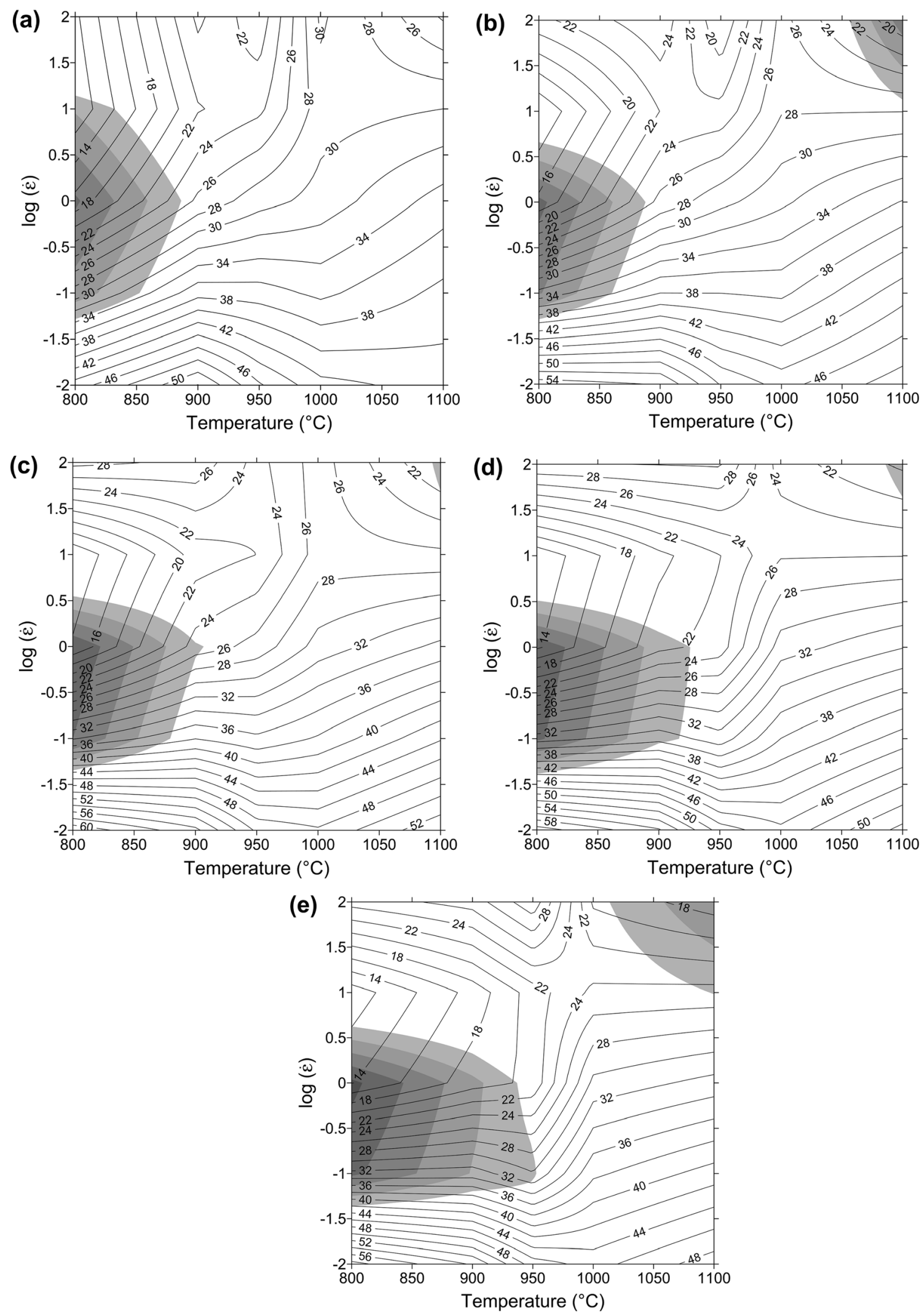

Fig. 4 Processing maps for Ti-6246 alloy developed on the basis of the Prasad criterion for the true strain of: (a) 0.2 , (b) 0.4 , (c) 0.6 , (d) 0.8 , (e) 1

material and are distributed unevenly, what in consequence will lead to decrease in formability of Ti-6246 alloy. The microstructure of the materials processed under the parameters shown in domains $\mathrm{A}$ and $\mathrm{B}$ confirms the 


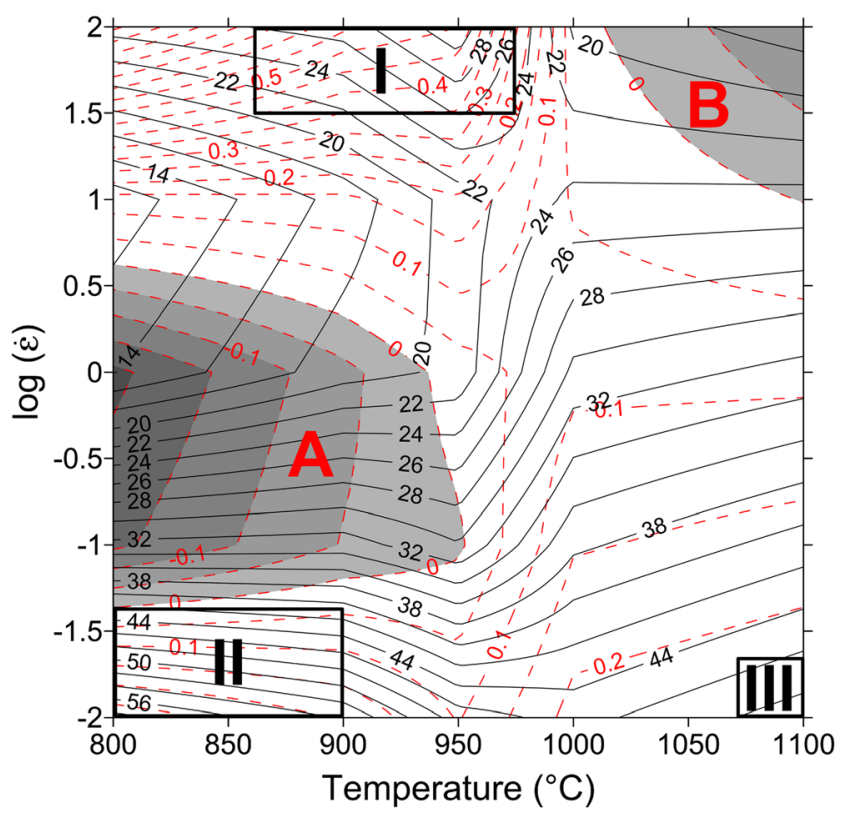

Fig. 5 Processing map for Ti-6246 alloy for the true strain of 1, with delineated processing windows

presence of instabilities in the microstructure and these domains will have to be avoided.

Figure 7 shows the microstructure of the specimens deformed in stability area, marked on the processing windows I-III shown in Fig. 5. In all cases, good quality and stability of the microstructures, without visible defects, can be observed. As noted earlier, Fig. 2(c) confirms, that DRX process occurs under these hot processing conditions. The microstructure obtained from the investigated alloy processed under parameters shown in processing window III (Fig. 7(d)) is characterized by a large grain size resulting from a grain growth occurring at the temperature of $1100{ }^{\circ} \mathrm{C}$ and low strain rate $0.01 \mathrm{~s}^{-1}$. The microstructure analysis gives a clear assessment of the flow stability of the investigated material and supports the expediency of elaborated processing windows for Ti6246 alloy.

\section{Hot forging}

The optimization and precise control of hot processing parameters for Ti-6246 alloy is possible by the analysis based on the processing maps elaborated for this alloy in conjunction with the numerical simulation of hot forging processes. This type of modeling of forging of selected structural parts was used by Wojtaszek and Śleboda [31] for describing the distribution of the temperature, state of stress and strain of P/M Ti6Al4V alloy. The optimal processing parameters used for the numerical modeling of forging Ti-6246 alloy part were chosen based on the processing map (Fig. 5) described in processing window I. Taking into account an increase of the forged part temperature during processing, the temperature of the billet was assumed as $900^{\circ} \mathrm{C}$.

For representing different parameters of forming process (strain, stress, temperature, filling of dies and so on) updated Lagrangian method was used in Qform 3D. In this program remeshing algorithm such as finite element mesh generation and remeshing during simulation are carried out automatically. The Automatic Mesh Generator produces optimized mesh and can modify the mesh when the acceptable criteria are violated. This system based on flow formulation and flow stress depends on deformation temperature, strain and strain rate. In the performed simulations elastic deformation was neglected and material was accepted as isotropic and incompressible. In the performed FE simulations, the mesh for the workpiece had a form of triangles. During the simulation process mesh density distribution changed depending on the shape of the forged part.

Figure 8 presents the results of the numerical modeling of forging selected part from Ti-6246 alloy, describing the distributions of finite element mesh (Fig. 8(a)), temperature (Fig. 8(b)), mean stress (Fig. 8(c)) and effective strain (Fig. 8(d)). Forging in the final impression, presented in Fig. 8(b), was accompanied by a rapid increase in the temperature in the flash and in the forged part surface. These high temperature regions should be associated with a high velocity of the upper tool resulting in the high amount of work of plastic deformation transforming into temperature increase. The distribution of
Fig. 6 The microstructure of the specimens deformed in instability domains corresponding to the following processing parameters: (a) $800{ }^{\circ} \mathrm{C} / 1 \mathrm{~s}^{-1}$, (b) $1100{ }^{\circ} \mathrm{C}$ $/ 100 \mathrm{~s}^{-1}$
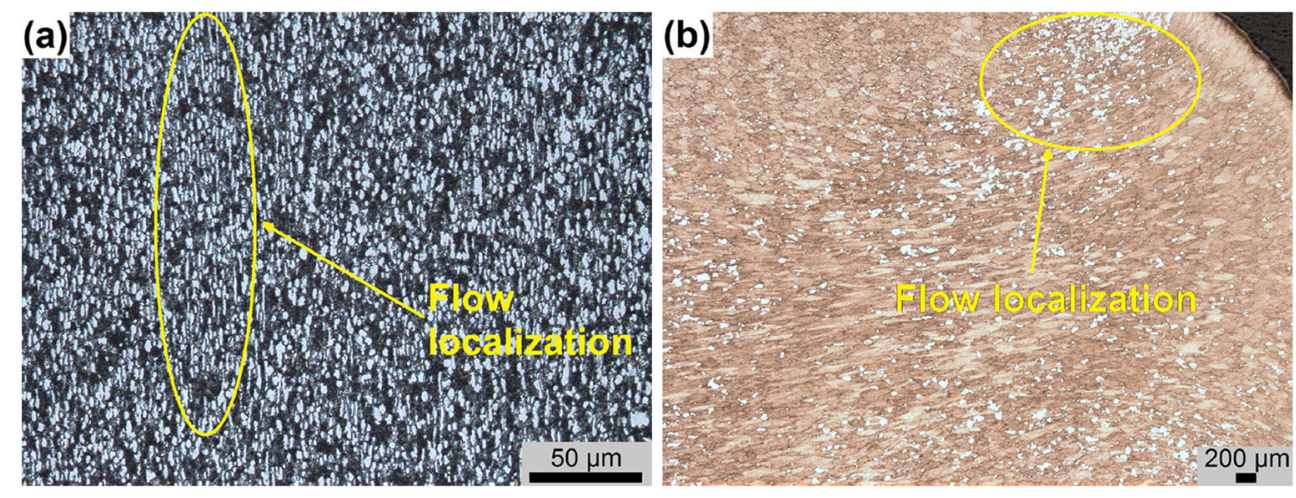
Fig. 7 The microstructures of the investigated specimens after deformation according to the parameters determined by processing windows I-III: (a) $900{ }^{\circ} \mathrm{C} / 100 \mathrm{~s}^{-1}$, (b) $800{ }^{\circ} \mathrm{C}$ $/ 0.01 \mathrm{~s}^{-1}$, (c) $900^{\circ} \mathrm{C} / 0.01 \mathrm{~s}^{-1}$, (d) $1100{ }^{\circ} \mathrm{C} / 0.01 \mathrm{~s}^{-1}$
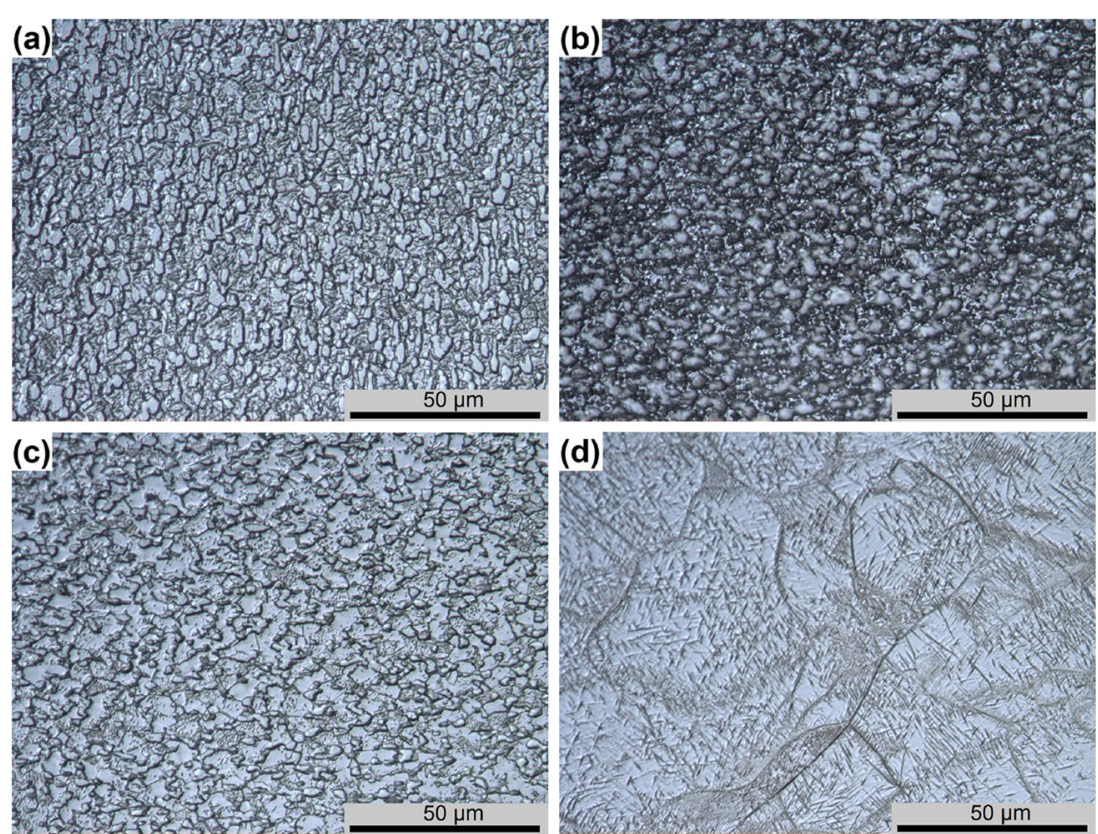

mean stress (Fig. 8(c)) is fairly uniform within a volume of the investigated part. Figure 8(d) shows an increase in effective strain level at the surface of the forged part, what can result from the occurrence of intense material flow in this area. (a)

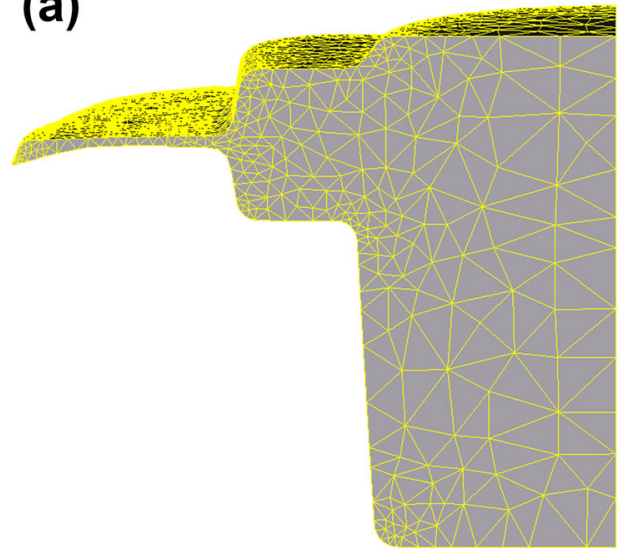

(c)

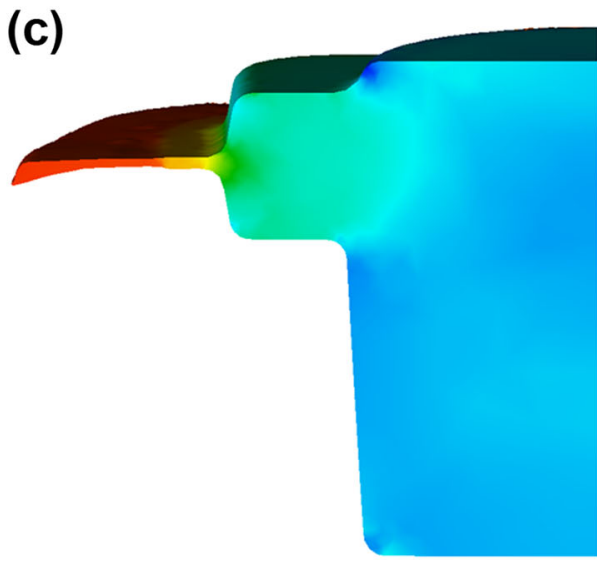

Mean Stress (MPa)

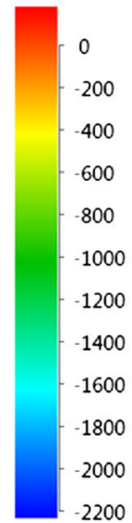

(b)

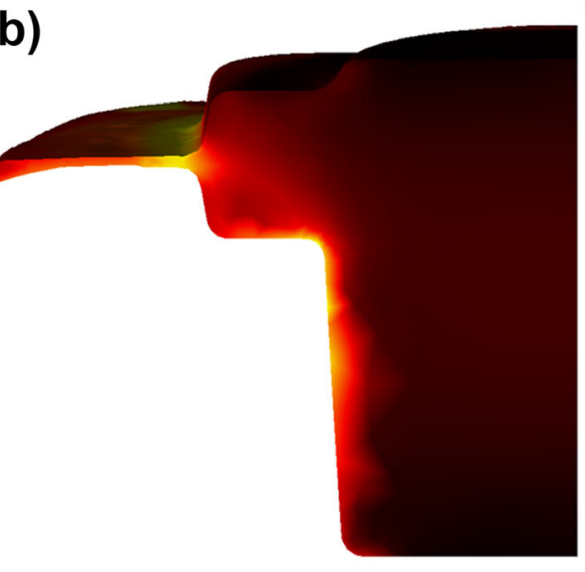

Temperature $\left({ }^{\circ} \mathrm{C}\right)$

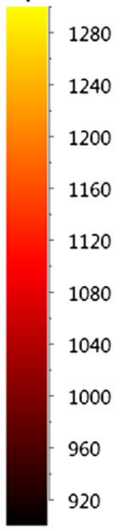

(d)

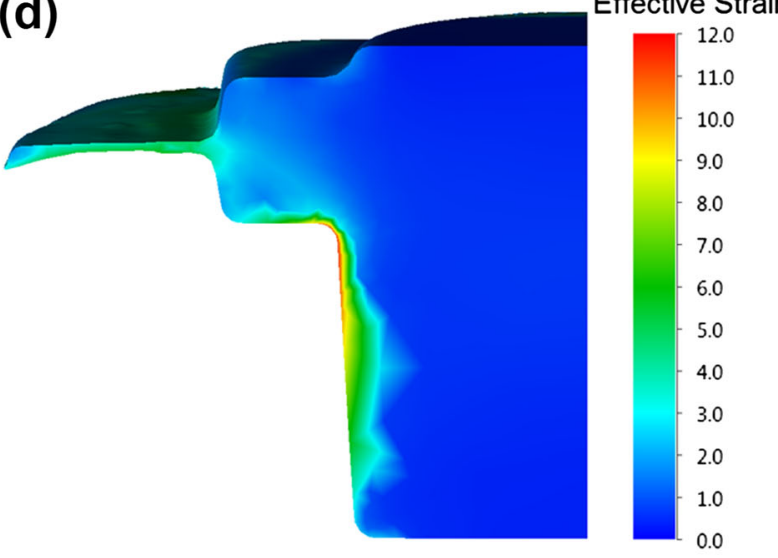

Fig. 8 Numerical distributions of finite element mesh (a), temperature (b), mean stress (c) and effective strain (d) in a Ti-6246 alloy forged part final impression 
Fig. 9 Forging obtained in industrial conditions: (a) forged part, (b) forged part model with selected sections used in computed tomography (CT) analysis, (c) CT image of YX cross-section, (d) CT image of ZX cross-section
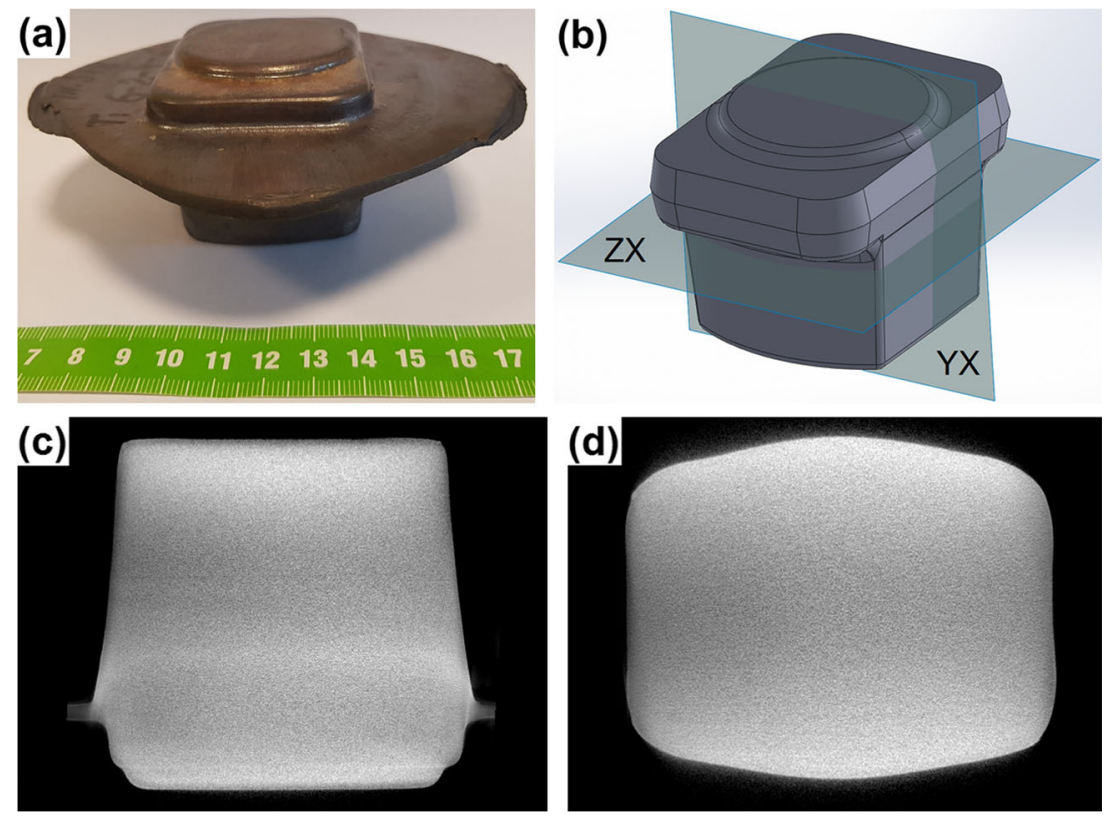

The complex analysis of the obtained results, based on the processing maps describing deformation behavior of Ti6246 alloy, microstructural validation and numerical modelling of forging, gives the opportunity to optimize the processing parameters of hot working such as the workpiece geometry and favorable forging parameters. Evaluation of these results was carried out by industrial forging tests realized in ATI ZKM Forging Company. The process of forging a Ti-6246 alloy part (Fig. 9(a)) consisted of two deformation stages, and was carried out on the $1 \mathrm{~T}$ hammer according to the processing parameters determined in processing window I. After forging, the selected part was cooled down by forced air. The quality of the obtained part was assessed by CT. Figure 9(b) shows the model of the investigated part with selected sections obtained in computed tomography (CT). The results of non-destructive testing (Fig. 9(c-d)) did not reveal cracks or any other defects in the volume of the material and confirmed the correctness of the selection of technological parameters and the feasibility of using the above techniques for optimization of hot working processing parameters of the investigated alloy.

\section{Summary}

Prasad criterion was used in this work for proper understanding of the hot deformation behavior of Ti-6246 alloy. The hot compression tests were conducted on Gleeble 3800 thermomechanical simulator at the temperature range of $800{ }^{\circ} \mathrm{C}$ to $1100{ }^{\circ} \mathrm{C}$, and strain rate range of 0.01 to $100 \mathrm{~s}^{-1}$. The flow stress curves were used to elaborate processing maps for the investigated alloy. The instability domain of this alloy can be observed at the strain rates ranging from 0.04 to $4 \mathrm{~s}^{-1}$ and temperature range of $800{ }^{\circ} \mathrm{C}-950{ }^{\circ} \mathrm{C}$, and also at the highest strain rates and temperatures, which should to be avoided in hot forming of Ti-6246 alloy. The analysis of the processing maps enables describing the areas of potentially favorable combinations of hot working parameters. The microstructure analysis supports the determination of Ti-6246 alloy behavior in a wide range of temperatures and strain rates. For optimization of hot deformation processing parameters, numerical modeling of forging selected part of the investigated alloy was conducted. Based on the complex analysis of the obtained results describing deformation behavior of Ti-6246 alloy, microstructural observations and numerical modeling of forging selected structural part, the industrial forging tests were realized. CT results did not reveal defects in the volume of the forged part and allowed to confirm the expediency of complex analysis performed for the optimization of hot processing of this alloy.

Acknowledgments Financial assistance of the National Science Centre Poland project No. UMO-2015/19/B/ST8/01079 is acknowledged.

Open Access This article is licensed under a Creative Commons Attribution 4.0 International License, which permits use, sharing, adaptation, distribution and reproduction in any medium or format, as long as you give appropriate credit to the original author(s) and the source, provide a link to the Creative Commons licence, and indicate if changes were made. The images or other third party material in this article are included in the article's Creative Commons licence, unless indicated otherwise in a credit line to the material. If material is not included in the article's Creative Commons licence and your intended use is not permitted by statutory regulation or exceeds the permitted use, you will need to obtain permission directly from the copyright holder. To view a copy of this licence, visit http://creativecommons.org/licenses/by/4.0/. 


\section{References}

1. Huda Z, Edi P (2013) Materials selection in design of structures and engines of supersonic aircrafts: a review. Mater Des 46(4):552-560. https://doi.org/10.1016/j.matdes.2012.10.001

2. Bhattachayya D, Viswanathan GB, Denkenberger R, Furrer D, Fraser HL (2003) The role of crystallographic and geometrical relationships between $\alpha$ and $\beta$ phases in an $\alpha / \beta$ titanium alloy. Acta Mater 51(16):4679-4691. https://doi.org/10.1016/S1359-6454(03) 00179-4

3. Boyer R, Collings EW, Welsch G (1994) Materials properties handbook: titanium alloys. ASM International, p 479

4. Glavicic MG, Bartha BB, Jha SK, Szczepanski CJ (2009) The origins of microtexture in duplex Ti alloys. Mater Sci Eng A 513-514:325-328. https://doi.org/10.1016/j.msea.2009.02.003

5. Krawczyk J, Łukaszek-Sołek A, Dąbrowski R (2015) The role of the deformation conditions in the evolution of the microstructure of Ti-6Al-2Sn-4Zr-6Mo alloy. Key Eng Mater 641:116-119. https:// doi.org/10.4028/www.scientific.net/KEM.641.116

6. Jackson M, Dashwood RJ, Christodoulou L, Flower HM (2002) Isothermal subtransus forging of Ti-6Al-2Sn-4Zr-6Mo. J Light Met 2(3):185-195. https://doi.org/10.1016/S1471-5317(02)00044-5

7. Tarín P, Alonso I, Simón AG, Badía JM, Piris NM (2008) Characterization of the $\alpha \leftrightarrow \beta$ transformations in a Ti-6Al-2Sn4Zr-6Mo (wt.\%) alloy. Mater Sci Eng A 481(1):559-561. https:// doi.org/10.1016/j.msea.2006.12.193

8. Dehghan-Manshadi A, Dippenaar RJ (2012) Strain-induced phase transformation during thermo-mechanical processing of titanium alloys. Mater Sci Eng A 552:451-456. https://doi.org/10.1016/j. msea.2012.05.069

9. Qiu J, Ma Y, Lei J, Liu Y, Huang A, Rugg D, Yang R (2014) A comparative study on dwell fatigue of Ti-6Al-2Sn-4Zr- $x \mathrm{Mo}(x=2$ to 6) alloys on a microstructure-normalized basis. Metall Mater Trans A 45(13):6075-6087. https://doi.org/10.1007/s11661-014-2541-5

10. Hémery S, Villechaise $P$ (2017) Comparison of slip system activation in Ti-6Al-2Sn-4Zr-2Mo and Ti-6Al-2Sn-4Zr-6Mo under tensile, fatigue and dwell-fatigue loadings. Mater Sci Eng A 697:177183. https://doi.org/10.1016/j.msea.2017.05.021

11. Prasad YVRK, Gegel HL, Doraivelu SM, Malas JC, Morgan JT, Lark KA, Barker DR (1984) Modelling of dynamic materials behavior in hot deformation: forging of Ti-6242. Metall Trans A 15(10):1883-1892. https://doi.org/10.1007/BF02664902

12. Prasad YVRK, Seshacharyulu T (1998) Processing maps for hot working of titanium alloys. Mater Sci Eng A 243(1-2):82-88. https://doi.org/10.1016/S0921-5093(97)00782-X

13. Luo J, Li M, Yu W, Li H (2009) Effect of the strain on processing maps of titanium alloys in isothermal compression. Mater Sci Eng A 504(1-2):90-98. https://doi.org/10.1016/j.msea.2008.10.020

14. Ning Y, Fu MW, Hou H, Yao Z, Guo H (2011) Hot deformation behavior of Ti-5.0Al- 2.40Sn-2.02Zr-3.86Mo-3.91Cr alloy with an initial lamellar microstructure in the $\alpha+\beta$ phase field. Mater Sci Eng A 528(3):1812-1818. https://doi.org/10.1016/j.msea.2010.11. 019

15. Wang KL, Lu SQ, Fu MW, Li X, Dong XJ (2010) Identification of the optimal $(\alpha+\beta)$ forging process parameters of Ti-6.5Al-3.5Mo$1.5 \mathrm{Zr}-0.3 \mathrm{Si}$ based on processing-maps. Mater Sci Eng A 527(2728):7279-7285. https://doi.org/10.1016/j.msea.2010.08.031

16. Li X, Lu S, Wang K, Fu MW, Cao C (2013) Analysis and comparison of the instability regimes in the processing maps generated using different instability criteria for Ti-6.5Al-3.5Mo-1.5Zr0.3Si alloy. Mater Sci Eng A 576:259-266. https://doi.org/10. 1016/j.msea.2013.03.087

17. Ma X, Zeng W, Sun Y, Zhao Y, Wang S, Zhou Y (2010) A comparative study of various flow instability criteria in processing map. Rare met mater Eng 39(5):756-761. https://doi.org/10.1016/S18755372(10)60096-3

18. Zhou G, Ding H, Cao F, Han Y, Zhang B (2012) Flow instability criteria in processing map of superalloy GH79. Trans nonferrous met Soc China 22:1575-1581. https://doi.org/10.1016/S10036326(11)61358-7

19. Wu F, Xu W, Jin X, Zhong X, Wan X, Shan D, Guo B (2017) Study on hot deformation behavior and microstructure evolution of Ti-55 high-temperature titanium alloy. Met 7:1-17. https://doi.org/10. 3390/met7080319

20. Yang Y, Liu L, Zhai T, Zhao C, Yu H, Li Q (2019) Formability of a HSAS based on hot processing maps and texture analyses. Mater res express 6:1-11. https://doi.org/10.1088/2053-1591/ab14ab

21. Lypchanskyi O, Zyguła K, Śleboda T, Wojtaszek M, ŁukaszekSołek A (2018) Characterization of Ti-6Al-2Sn-4Zr-6Mo alloy flow behaviour using Malas's stability criterion. IOP Conf Ser: Mater Sci Eng 461:1-6. https://doi.org/10.1088/1757-899X/461/ $1 / 012048$

22. Ma X, Zeng WD, Wang KX, Lai Y, Zhou Y (2012) The investigation on the unstable flow behavior of Ti17 alloy in $\alpha+\beta$ phase field using processing map. Mater Sci Eng A 550:131-137. https://doi. org/10.1016/j.msea.2012.04.045

23. Prasad YVRK, Rao KP (2005) Processing maps and rate controlling mechanisms of hot deformation of electrolytic tough pitch copper in the temperature range $300-950{ }^{\circ} \mathrm{C}$. Mater Sci Eng A 391(12):141-150. https://doi.org/10.1016/j.msea.2004.08.049

24. Liu J, Cui Z, Li C (2008) Analysis of metal workability by integration of FEM and 3-D processing maps. J Mater Process Technol 205(1):497-505. https://doi.org/10.1016/j.jmatprotec.2007.11.308

25. Prasad YVRK (2003) Processing maps: a status report. J Mater Eng Perform 12(6):638-645. https://doi.org/10.1361/ 105994903322692420

26. Prasad YVRK, Sasidhara S (1997) Hot working guide: a compendium of processing maps. ASM International

27. Chen H, Liu X, Liu G, Tang X, Luo J, Feng Y, Li J, Fu H (2016) Hot deformation behavior and processing map of Ti-6Al-3Nb-2Zr1Mo titanium alloy. Rare Metal Mater and Eng 45(4):901-906. https://doi.org/10.1016/S1875-5372(16)30097-2

28. Wang K, Zeng W, Zhao Y, Lai Y, Zhou Y (2010) Hot working of Ti17 titanium alloy with lamellar starting structure using 3-D processing maps. J Mater Sci 45(21):5883-5891. https://doi.org/10.1007/ s10853-010-4667-1

29. Du Z, Jiang S, Zhang K (2015) The hot deformation behavior and processing map of Ti-47.5Al-Cr-V alloy. Mater Des 86:464-473. https://doi.org/10.1016/j.matdes.2015.07.027

30. Sieniawski J, Motyka M (2007) Superplasticity in titanium alloys. J Achiev Mater Manuf Eng 24(1):123-130

31. Wojtaszek M, Śleboda T (2014) Design and verification of thermomechanical parameters of P/M Ti6Al4V alloy forging. J Alloys Compd 615:546-550. https://doi.org/10.1016/j.jallcom. 2014.01.161

Publisher's note Springer Nature remains neutral with regard to jurisdictional claims in published maps and institutional affiliations. 